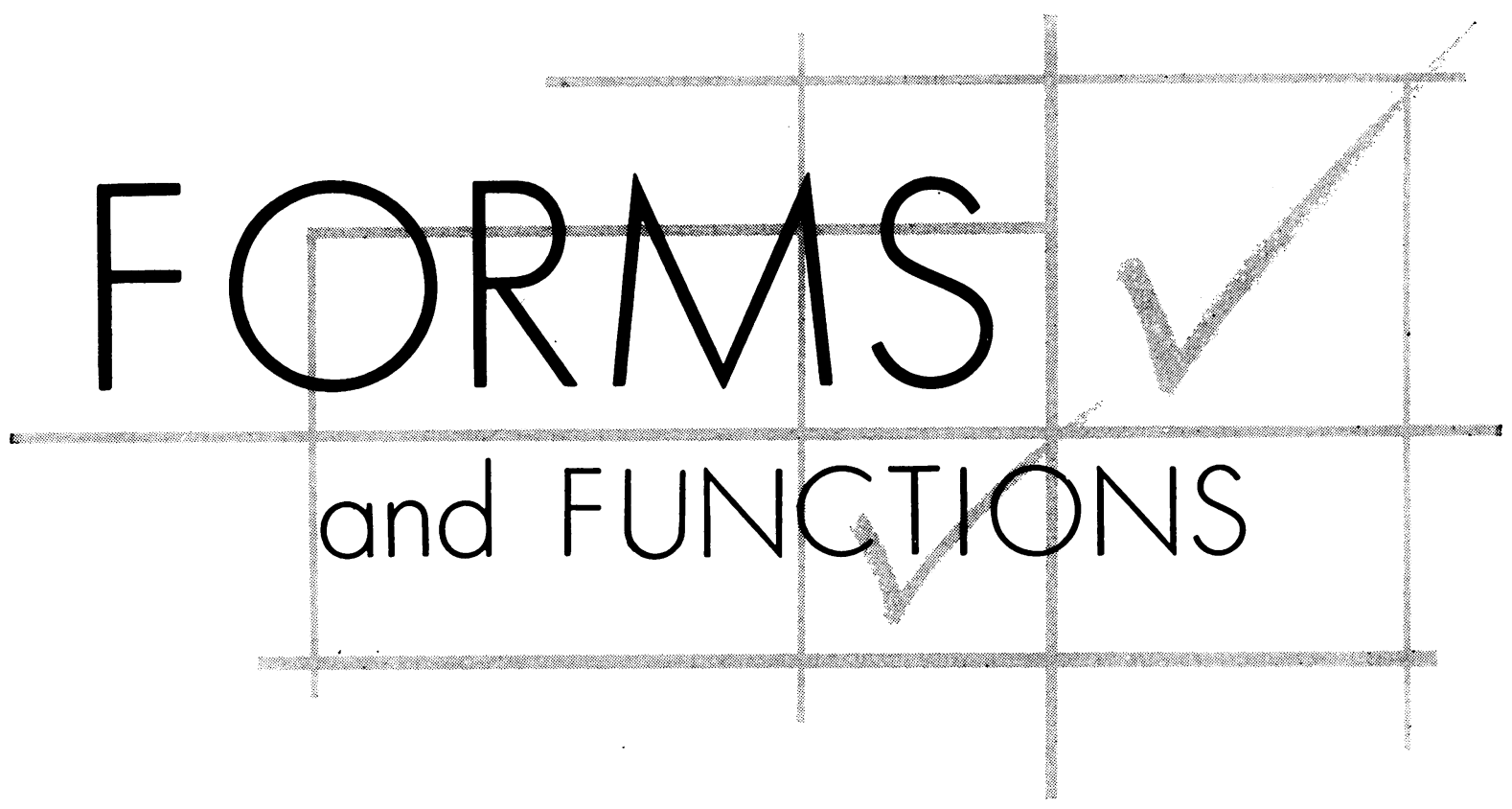

By CHARLES L. WILBAR, JR., M.D.

$\mathrm{I}^{\mathrm{s}}$ S THERE any public health worker who has not said, at least to himself: Is this form that is being filled out for the department of health really useful? Does it give the data that are sought? Are the data being put to good use? Are the statements on the form so clear that the various people filling it out readily understand what information is desired?

The time spent in compiling and completing the various forms used by any public health agency is considerable. Consequently, having forms carefully designed to obtain specific data is an important factor in the efficient operation of the agency.

Perhaps there is no such thing as a faultless form. However, during the past 3 years the Pennsylvania Department of Health has been working toward that goal. It is certainly not the first health agency to be concerned with improvement of forms, but some of the methods

Dr. Wilbar is the deputy secretary of health, Penn. sylvania Department of Health, Harrisburg. During the 1940's and 1950's, he was with the Hawaii Department of Health, first as chief of the bureau of maternal and child health and then as president of the Board of Health. used and the results obtained may be unusual enough to be of interest to other public health agencies.

\section{Review and Study}

In August 1953, the State health officer of Pennsylvania appointed a Committee on Records and Forms, comprised of top administrators from several units of the department of health. The deputy health officer was appointed chairman. Other members were the director of the bureau of statistics and records, the director of the bureau of tuberculosis, the assistant director of the bureau of sanitary engineering, the chief of the division of biologicals and supplies, and a regional public health nursing consultant. After the first year, a procedure analyst, the first to be employed by the department, joined the committee and became a key person in its activities. (The department now employs three procedure analysts.)

During the first year, the committee began to review in detail all forms used in the department and all new forms proposed. It met once each week. Unit directors were present when the forms for their units were being reviewed. 
At first, some of the unit directors felt that the questions asked by the committee were inquisitorial, but, as the results of the committee's work became apparent, a rather general appreciation of its ends developed and the means to those ends became more acceptable.

A form entitled "Request for Form Approval" was instituted and required as an accompaniment of all orders for forms, either new forms or old ones. After the procedure analyst joined the committee, he reviewed the forms of the department which had not yet been covered, conferred directly with the unit administrators concerned, suggested changes where necessary, and then reported back to the committee. This meant that the committee had less detail to consider and therefore needed to meet less frequently. It now meets monthly.

At its first meeting the committee adopted the following definition of a form: any printed or otherwise reproduced record on which there is space provided for the insertion of pertinent data which is repeatedly used by the State department of health or any of its units. Thus pamphlets, posters, and other health education literature were considered outside the jurisdiction of the committee.

The committee set up certain standards for all forms, including paper specifications, uniform department headings, volume of storage supply, and a numbering system. Form numbers are assigned by the supply unit of the department. The supply unit maintains a general register of all forms, and each major unit of the department maintains a register for the forms it uses.

Since any change in procedure is bound to cause a "raising of eyebrows," if not a "throwing up of hands," the committee has attempted from time to time to acquaint the departmental staff not only with its actions but also with the reasons therefor. Records and forms have been discussed at several of the monthly meetings of the department's administrative staff, and one of these meetings was given over almost entirely to the subject. Circular letters have been distributed as the need for them became apparent. Unit directors who have any suggestions or complaints are always welcome to attend the committee meetings.

\section{The Committee's Accomplishments}

As a result of the committee's work, there has been a marked reduction in the number of forms used by the department of health. For example, in one bureau the number has been decreased from 396 to 186 .

A considerable reduction in the cost of printing some forms has been achieved. The cost of reproducing one form, for example, was reduced from $\$ 4,800$ to $\$ 2,500$ for a year's supply. Savings in cost have been brought about by reducing paper volume of some forms, by ordering in quantities that permit the greatest savings without overstocking, and by multilithing instead of printing or mimeographing certain forms. Reduction in paper volume has been achieved by improving format and sometimes by omitting unnecessary items.

Some standardization and integration of forms has been accomplished. The diversity of headings once found on the department's forms and stationery has largely been eliminated. Forms used for similar purposes now have similar design. They may not be exactly the same in content, but their similarity of arrangement makes it much easier than before to fill out the various forms. For instance, forms used in different clinics formerly had similar items scattered in different places. Now there is more uniformity of arrangement, making the task of the public health nurse working in the various clinics much easier.

Probably the most significant accomplishment of the committee has been its demonstration to administrators in the department of the value of good records and of the relationship of records and forms to the philosophy and formulation of program direction. It has become apparent to most administrators that poorly designed forms can waste both time and money. The move toward uniformity of forms has made administrators more aware of the problems faced by other units of the department and the way the various programs mesh into the whole program of the department.

The establishment of a stocking procedure for forms, according to an approved plan, has seemed to add to the efficiency of the department. In the past some forms had been printed in quantities which, at the rate of usage, would last many years. Not only did these 
forms take up excessive storage space, but often changing conditions meant that the forms would be changed. Thus the department was faced with either discarding large quantities of the form or of using a form that was not up to date. Understocking of forms meant not only the danger of running out of forms before new ones could be obtained, but also the extra expense of reproducing small quantities frequently.

As with nearly all standards, exceptions must of course be made. Uniformity is desirable, but it is not always feasible and advisable. The department administers the State tuberculosis sanatoriums and also a crippled children's hospital. Certain forms of these institutions have been made uniform, but we have found that all cannot be so because of differences in patients between the tuberculosis institutions and the crippled children's hospital. The committee is presently trying to bring about some uniformity in the patient index cards and in the social history forms used by various units in the department. The diversity of types of patients seen will prevent complete uniformity in these forms, but a much greater similarity among them is possible and desirable.

\section{Summary}

Since compiling and completing forms is a time-consuming activity for public health workers, having the makeup of forms as nearly faultless as possible is an efficiency essential.

A committee of top administrators in the Pennsylvania Department of Health, assisted by a procedure analyst, has reviewed all the department's forms during the past 3 years. All new or reordered forms must be approved by this committee.

Activities of the committee have brought about a marked reduction in the number of forms, an appreciable reduction in the cost of printing some of the forms, and some standardization and integration of various forms.

Department administrators have developed an increasing awareness of the relationship of records and forms to program formulation and direction in their own units and throughout the whole department.

\section{Radioactivity Survey in Staple Foods}

A continuous survey of radioactivity in selected foods throughout the Nation has been launched by the Food and Drug Administration. Instructions inaugurating the program were issued in December 1956.

The initial goal of the program is to determine the natural "background radioactivity" in foods from different areas. These foods will then be monitored for changes in radioactivity caused by weapon testing or other uses of atomic energy.

A search is now under way for canned foods packed before 1945"year one" of the atomic age; these products will be valuable in fixing a base for future radiation measurements. FDA is also collecting samples of recently packed foods for comparison.

Covered by the survey are 12 staple foods, including potatoes, wheat, corn, dried fruit, liquid milk, bread, and canned tomatoes. Arrangements are being made to sample imported foods as well. 